\title{
Morfologia dos tricomas das pétalas de espécies de Pseudobombax Dugand (Malvaceae, Bombacoideae) e seu significado taxonômico ${ }^{1}$
}

\author{
Jefferson Guedes de Carvalho-Sobrinho ${ }^{2,3}$, Francisco de Assis Ribeiro dos Santos ${ }^{3}$ e Luciano Paganucci de Queiroz ${ }^{3}$
}

Recebido em 20/08/2008. Aceito em 19/12/2008

RESUMO - (Morfologia dos tricomas das pétalas de espécies de Pseudobombax Dugand (Malvaceae, Bombacoideae) e seu significado taxonômico). O gênero Pseudobombax Dugand apresenta cerca de 30 espécies, é restrito à região Neotropical e apresenta taxonomia complexa, com muitas de suas espécies mal circunscritas. Parte de seus problemas taxonômicos é conseqüência do fato de que suas espécies perdem as folhas na floração e, portanto, a maioria delas é representada apenas por flores nas coleções de herbário. Neste trabalho, investigou-se a morfologia dos tricomas presentes nas pétalas de oito espécies de Pseudobombax. O estudo utilizou microscopia óptica e eletrônica de varredura a partir de amostras obtidas de material de herbário e flores fixadas em etanol a 70\%. Em todas as espécies de Pseudobombax analisadas, foram encontrados dois tipos principais de tricomas: (a) tricomas 2-4-armados, sésseis, longos, flexíveis e com paredes finas, situados na face adaxial de todas as espécies; (b) tricomas tufosos, sésseis, curtos, rígidos, com paredes espessas e lignificadas, situados na face abaxial. Os dados qualitativos e quantitativos obtidos mostraram-se de valor taxonômico para a resolução de problemas de identificação específica em Pseudobombax.

Palavras-chave: Morfologia, tricomas, Pseudobombax, Malvaceae

ABSTRACT - (Morphology of trichomes in petals of Pseudobombax Dugand (Malvaceae, Bombacoideae) species and its taxonomic significance). Trichome morphology of the petals of Pseudobombax Dugand species was investigated. The eight species selected of Pseudobombax were analyzed using optical microscopy and scanning electron microscopy. The study detected the existence of variation, both qualitative and quantitative, in morphology of trichomes in petals of species analyzed. In Pseudobombax petals, two kinds of trichomes were found: (a) trichomes 2-4-armed, sessile, long, flexible and with thin walls, situated on the adaxial surface; (b) tufted trichomes, sessile, short, rigid, with thick, lignified walls, on the abaxial surface of the petals. The qualitative and quantitative data were of taxonomic value for the resolution of problems of specific identification in the genus.

Key words: Morphology, trichomes, Pseudobombax, Malvaceae

\section{Introdução}

O gênero Pseudobombax Dugand é representado por cerca de 20 espécies com distribuição na região Neotropical (Robyns 1963; 1967; Fernández-Alonso 2001). Pertence à subfamília Bombacoideae da família Malvaceae (Alverson et al. 1999; Bayer et al. 1999; Baum et al. 2004; Nyffeler et al. 2005) e caracteriza-se pelo hábito arbóreo, tronco com estrias longitudinais verdes, folhas digitadas, ápice do pecíolo dilatado, folíolos não articulados com o pecíolo, receptáculo glanduloso e anteras hipocrepiformes. As pétalas são carnosas e indumentadas em ambas as faces (Robyns 1963).

As espécies de Pseudobombax são tradicionalmente diagnosticadas com base em caracteres vegetativos, entre eles o número, forma e indumento dos folíolos e o comprimento do pecíolo e do peciólulo (Robyns 1963). No entanto, devido à deciduidade da folhagem durante a floração, a maioria das espécies de Pseudobombax é representada nos herbários por exsicatas incompletas, geralmente apresentando apenas flores. Resulta disso que os limites interespecíficos são imprecisos e os espécimes encontram-se, na sua maioria, mal identificados.

Algumas espécies apresentam sobreposição em caracteres vegetativos tornando seus limites taxonômicos imprecisos, como é o caso de Pseudobombax grandiflorum (Cav.) A.Robyns em relação a P. longiflorum (Mart. \& Zucc.) A. Robyns e também de P. marginatum (A. St.-Hil., Juss. \& Cambess.) A.Robyns em relação a $P$. tomentosum (Mart. \& Zucc.) A. Robyns. Assim, a descoberta de novas fontes de caracteres taxonômicos nos frutos e principalmente nas flores é de grande importância para a identificação das espécies do gênero, representando uma contribuição significativa para o seu conhecimento taxonômico (G.L. Esteves, comunicação pessoal). A ocorrência de tricomas nas pétalas de Pseudobombax é um caráter morfológico considerado diagnóstico para o gênero por Robyns (1963). Este autor denominou-os de "tricomas em buquê" sem, no entanto, fornecer informações detalhadas sobre a sua morfologia, tais como o número de células ou de ramos, disposição dos ramos, comprimento do tricoma e forma de inserção na epiderme.

Estudos sobre a morfologia de tricomas têm demonstrado importância taxonômica na delimitação de subgêneros e espécies de Labiatae (Demissew \& Harley 1992), Melastomataceae (Guimarães et al. 1999) e Campanulaceae (Batterman \& Lammers 2004). Nas Malvales, Salma (1999) encontrou variações nos tricomas em folhas de Durio Adans. (Malvaceae, Helicteroideae) que foram utilizadas na delimitação de espécies. No entanto, não há na literatura descrições detalhadas sobre a morfologia de tricomas em Bombacoideae, que têm sido descritos apenas ao nível do indumento, sendo a variação micromorfológica pouco referida, especialmente em se tratando de tricomas nas flores.

O objetivo deste trabalho foi investigar a morfologia dos tricomas das pétalas das espécies de Pseudobombax a fim de identificar caracteres que possam subsidiar a taxonomia do grupo, verificando a possibilidade de aplicação de caracteres derivados desses tricomas na separação de $P$. grandiflorum de P. longiflorum e de P. marginatum de P. tomentosum.

\footnotetext{
Parte da Dissertação de Mestrado do primeiro Autor

2 Programa de Pós-Graduação em Botânica da Universidade Estadual de Feira de Santana

3 Universidade Estadual de Feira de Santana, Departamento de Ciências Biológicas, Feira de Santana, BA, Brasil Autor para correspondência: jef.sobrinho@gmail.com
} 


\section{Material e métodos}

Tricomas das pétalas de oito espécies de Pseudobombax (Tab. 1) foram estudados a partir de amostras retiradas de material de herbário e de material fixado em etanol 70\% (apenas para P. parvifolium sp. nov. inéd). Para cada espécie foram seccionadas duas amostras, com $1 \mathrm{~cm}^{2}$ cada, do terço médio de uma pétala. Em seguida, procedeu-se à reidratação do material através de aquecimento em microondas (potência máxima, $3 \mathrm{~min}$ ) em solução aquosa de glicerina (50\%). Uma amostra de cada espécie foi colocada em placa de Petri com água para posterior diafanização, sendo a outra seccionada transversalmente à mão livre para a análise da inserção dos tricomas na epiderme.

O processo de diafanização seguiu as seguintes etapas: imersão em hidróxido de sódio a $30 \%$ por duas horas, seguido de hipoclorito de sódio a $6,5 \%$ por 24 horas, lavagem em água destilada por duas vezes ( 30 minutos cada), série etanólica crescente $(30 \%, 50 \%, 70 \%)$, coloração com safranina a $1 \%$ em álcool $50 \%$ por uma hora, série etanólica decrescente $(70 \%, 50 \%$, $30 \%, 10 \%)$, lavagem em água destilada e acondicionamento em solução aquosa de glicerina (50\%) para posterior análise (Macêdo 1997).

Os cortes transversais obtidos, à mão livre, foram colocados em hipoclorito de sódio a $6,5 \%$, permanecendo até o clareamento total (cerca de uma hora). Logo após, os cortes foram lavados em água destilada, corados com safranina $1 \%$ durante dois minutos, lavados novamente e colocados em solução aquosa de glicerina (50\%) por uma hora. As amostras foram montadas em lâminas com gelatina glicerinada, seladas com esmalte, analisadas em microscópio óptico e, em seguida, fotomicrografadas com uma câmera digital Olympus 4.2 megapixels.

A partir da análise do material ao microscópio óptico, foram obtidos dados referentes à forma, número de ramos, comprimento total médio e densidade média dos tricomas na superfície das pétalas. No caso dos dados quantitativos, a média foi calculada a partir de 10 medições para cada parâmetro analisado. Os dados de comprimento dos tricomas da face adaxial são referentes aos tricomas situados na faixa longitudinal em que se apresentam mais longos. A classificação e a terminologia utilizada para a descrição dos tricomas foram baseadas em Theobald et al. (1950), Payne (1978) e Hewson (1988).

Para análise em Microscopia Eletrônica de Varredura (MEV), foram obtidas amostras de $25 \mathrm{~mm}^{2}$ das faces abaxial e adaxial das pétalas, que foram fixadas em porta-espécimes, cobertas com cobre/ouro no metalizador SCD 050 e analisadas no microscópio eletrônico de varredura LEO 1430 VP. Foram tomadas eletromicrografias da superfície das pétalas, destacando os tricomas presentes.

\section{Resultados}

Foram encontrados tricomas nas faces adaxial (interna) e abaxial (externa) das pétalas de todas as espécies analisadas (Fig. 1-15). Na face adaxial, são encontrados tricomas 2-4-armados, sésseis, longos, flexíveis e com paredes finas, situados na face adaxial de todas as espécies (Fig. 1-2, 10-11). Na face abaxial, os tricomas são tufosos, sésseis, curtos, rígidos, com paredes espessas e lignificadas (Fig. 3-10, 12-15). Os tricomas da face adaxial conferem uma textura macia ao toque enquanto os encontrados na face abaxial conferem uma textura áspera.

Em ambos os tipos de tricomas, cada ramo é constituído por uma única célula, mas todos os ramos são fusionados em grupos. Os ramos são inseridos diretamente na epiderme, sendo diferenciados em corpo e base. A porção basal é fusionada e parcialmente inserida na epiderme. Nos tricomas 2-4-armados, o corpo é sempre maior do que a base (Fig. 1-2), enquanto nos tricomas tufosos a base pode ser maior que o corpo (Fig. 7-8, 15).

A face adaxial apresenta tricomas distribuídos em duas faixas longitudinais: uma constituída por tricomas com ramos relativamente mais longos, e outra por tricomas com ramos mais curtos (Fig. 11). Esses tricomas apresentaram maior comprimento em $P$. marginatum e $P$. tomentosum, atingindo até $1.000 \mu \mathrm{m}$ de comprimento (Tab. 1). Dentre as espécies estudadas, apenas $P$. grandiflorum e $P$. longiflorum apresentaram o terço basal da pétala glabro.

$\mathrm{Na}$ face abaxial, os tricomas tufosos apresentam-se com comprimento médio menor do que os tricomas 2-4-armados da face adaxial. Na maioria das espécies, os tricomas tufosos apresentam comprimento entre $300-400 \mu \mathrm{m}$. Apenas $P$. marginatum e $P$. parvifolium apresentam tricomas menores, variando entre 220-300 $\mu \mathrm{m}$ e 170-230 $\mu \mathrm{m}$, respectivamente.

Os tricomas tufosos, encontrados na face abaxial, apresentam o corpo com 6 a 25 ramos, enquanto a base pode ser ligeiramente constricta na porção situada no nível da epiderme (Fig. 10). Os ramos desses tricomas estão fusionados de forma a conferir um aspecto de um tufo à estrutura formada, podendo ser mais aberto e com maior diâmetro em P. grandiflorum (Fig. 6, 13) e mais fechado e mais alongado em P. tomentosum (Fig. 9, 15). Foram observadas, também, estruturas intermediárias às destas espécies (Fig. 3, 4, 7).

Os tricomas tufosos mostraram uma variação contínua em relação ao comprimento nas espécies analisadas, sendo os maiores encontrados em $P$. tomentosum e os menores em $P$. parvifolium. A maioria das espécies apresenta uma grande amplitude em densidade de tricomas, sendo que $P$. longiflorum e P. simplicifolium foram as que apresentaram os menores valores médios (Tab. 1). Em P. longiflorum e $P$. campestre, os tricomas tufosos se distribuem de forma concentrada em faixas perpendiculares ao eixo maior pétala (Fig. 12).

No que se refere à densidade dos tricomas tufosos, $P$. grandiflorum e Pseudobombax parvifolium foram as espécies com maior destaque, enquanto que $P$. longiflorum foi a espécie com menor número de tricomas por área (Tab. 1).

\section{Discussão}

Nomenclatura dos tricomas tufosos - Os tricomas ramificados encontrados nas Malvales têm sido designados genericamente como tricomas estrelados (Theobald et al. 1950; Foster 1966; Esteves 1998; 2001), sendo a sua presença considerada uma sinapomorfia morfológica da ordem (APG II 2003). No entanto, sob essa denominação há tricomas com morfologia muito variável (Theobald et al. 1950; Uphof 1962; Hummel \& Staesche 1962; Inamdar \& Chohan 1969). Uphof (1962) indicou a presença de tricomas em diferentes órgãos das plantas nas Malvales, que são constituídos por até oito células e conferem o aspecto morfológico característico dos tricomas estrelados da ordem.

O termo "tricoma estrelado" pode representar estruturas diferentes, de acordo com conceitos de autores distintos. Assim, tal termo pode expressar um tricoma pedunculado, com ramificações num mesmo plano (Esau 1965; Alquini et al. 2003), ou significar que essas ramificações podem 


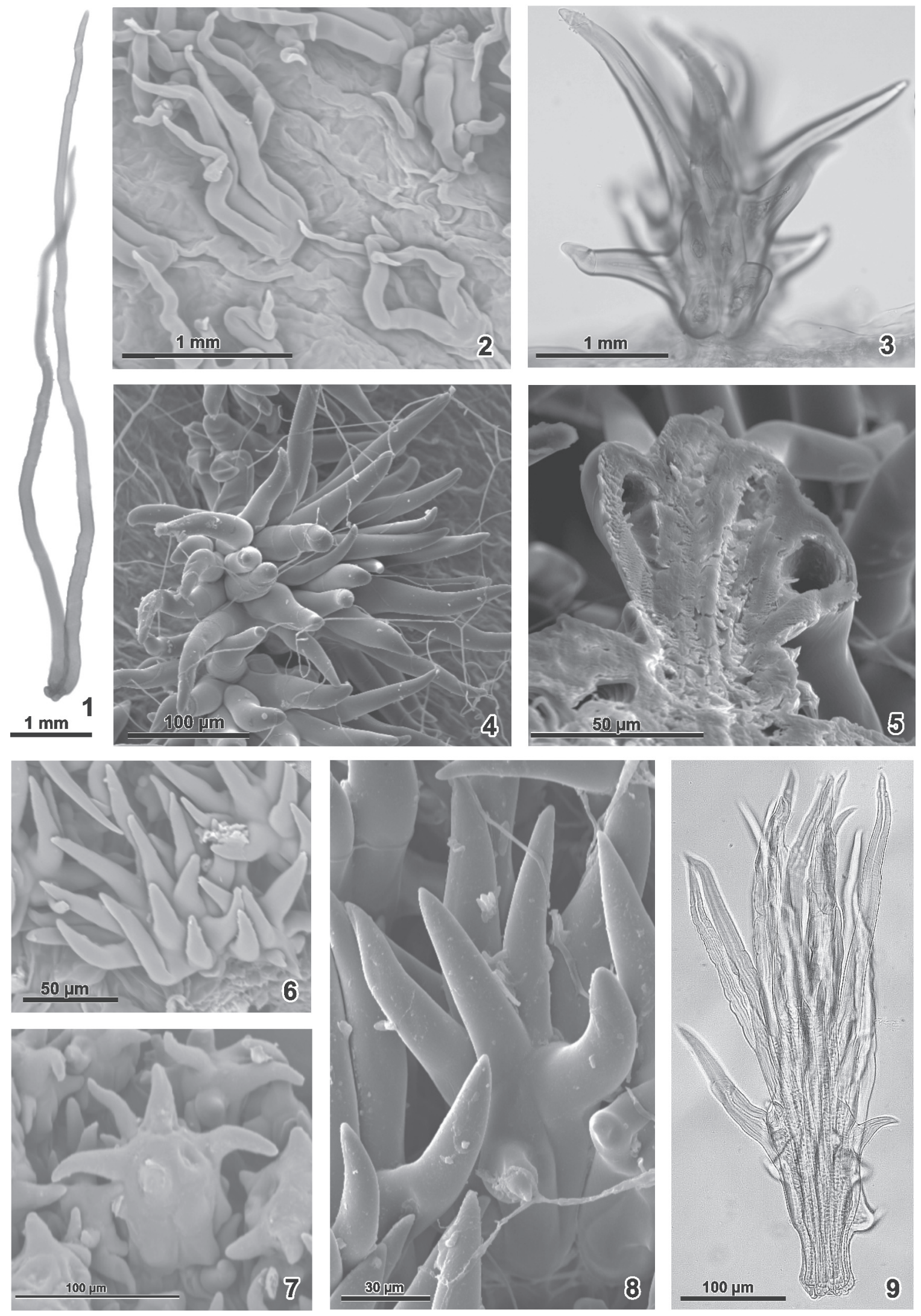

Figuras 1-9. Tipos de tricomas nas pétalas de Pseudobombax Dugand. 1-2. Tricomas 2-4-armados da face adaxial das pétalas de P. campestre (1) e P. grandiflorum (2). 3-9. Tricomas tufosos. 3-5. P. longiflorum: tricomas com mais de 20 ramos (4), parede celular espessa e lúmen reduzido (5). 6. P. grandiflorum. 7. P. minimum: ramos curtos em relação à base. 8. P. marginatum: ramos relativamente mais curtos que P. tomentosum. 9. P. tomentosum, ramos mais longos, orientados verticalmente. (Fig. 2-8: MEV). 
Tabela 1. Dados qualitativos e quantitativos dos tricomas das faces adaxial e abaxial de pétalas de Pseudobombax Dugand (Malvaceae, Bombacoideae) e material utilizado para análise em microscopia óptica e eletrônica de varredura.

\begin{tabular}{|c|c|c|c|c|c|}
\hline \multirow{2}{*}{ Espécie } & \multirow{2}{*}{$\begin{array}{c}\text { Face adaxial } \\
\text { Compr. total } \\
(\mu \mathrm{m})^{2}\end{array}$} & \multicolumn{3}{|c|}{ Face abaxial } & \multirow{2}{*}{ Material examinado } \\
\hline & & $\begin{array}{c}\text { Compr. } \\
\text { total }(\mu \mathrm{m})^{2}\end{array}$ & $\begin{array}{l}\mathrm{N}^{\mathrm{o}} \cdot \mathrm{de} \\
\text { ramos }\end{array}$ & $\begin{array}{l}\text { Densidade por } \\
2.500 \mu \mathrm{m}^{2}\left({ }^{2}\right)\end{array}$ & \\
\hline Pseudobombax campestre (Mart. \& Zucc.) A. Robyns & $\begin{array}{c}475 \\
(370-650)\end{array}$ & $\begin{array}{c}371 \\
(300-410)\end{array}$ & $8-25$ & $\begin{array}{c}14,4 \\
(12-18)\end{array}$ & $\begin{array}{l}\text { BRASIL. Bahia: Rio de Contas. 23/VIII/2000, } \\
\text { L.P. de Queiroz et al. } 6338 \text { (HUEFS) }\end{array}$ \\
\hline Pseudobombax grandiflorum (Cav.) A. Robyns & $\begin{array}{c}850 \\
(810-900)\end{array}$ & $\begin{array}{c}367 \\
(290-430)\end{array}$ & $8-18$ & $\begin{array}{c}18,3 \\
(15-23)\end{array}$ & $\begin{array}{l}\text { BRASIL. Espírito Santo: Linhares, 2/IX/1998, } \\
\text { D.A. Folli } 3240 \text { (HUEFS) }\end{array}$ \\
\hline Pseudobombax longiflorum (Mart. \& Zucc.) A. Robyns & $\begin{array}{c}594 \\
(470-670)\end{array}$ & $\begin{array}{c}325 \\
(300-400)\end{array}$ & $9-19$ & $\begin{array}{c}6,3 \\
(5-8)\end{array}$ & $\begin{array}{l}\text { BRASIL. Minas Gerais: Joaquim Felício, 17/ } \\
\text { VI/1990, J.R. Pirani et al. } 13200 \text { (SPF) }\end{array}$ \\
\hline $\begin{array}{l}\text { Pseudobombax marginatum (A.St.-Hil., Juss. \& } \\
\text { Cambess.) A. Robyns }\end{array}$ & $\begin{array}{c}1144 \\
(920-1350)\end{array}$ & $\begin{array}{c}240 \\
(220-300)\end{array}$ & $6-13$ & $\begin{array}{l}13,4 \\
(8-17)\end{array}$ & $\begin{array}{l}\text { BRASIL. São Paulo: Jales, 16/IV/1950, F.C. } \\
\text { Hoehne s/n (SPF) }\end{array}$ \\
\hline Pseudobombax minimum sp. nov. inéd. ${ }^{1}$ & $\begin{array}{c}770 \\
(700-890)\end{array}$ & $\begin{array}{c}340 \\
(280-410)\end{array}$ & $6-12$ & $\begin{array}{c}15,5 \\
(11-20)\end{array}$ & $\begin{array}{l}\text { BRASIL. Bahia: Riachão das Neves, 3/VI/1999, } \\
\text { E. Melo et al. } 2763 \text { (HUEFS) }\end{array}$ \\
\hline Pseudobombax parvifolium sp. nov. inéd. ${ }^{1}$ & $\begin{array}{c}810 \\
(600-1050)\end{array}$ & $\begin{array}{c}200 \\
(170-230)\end{array}$ & $6-11$ & $\begin{array}{c}18 \\
(14-20)\end{array}$ & $\begin{array}{l}\text { BRASIL. Bahia: Tanquinho, 24/XI/1991, I. } \\
\text { Crepaldi \& M. V. Oliveira 06 (HUEFS) }\end{array}$ \\
\hline Pseudobombax simplicifolium A. Robyns & $\begin{array}{c}632 \\
(530-840)\end{array}$ & $\begin{array}{c}332 \\
(250-400)\end{array}$ & $7-9$ & $\begin{array}{c}9,4 \\
(7-12)\end{array}$ & $\begin{array}{l}\text { BRASIL. Bahia: Casa Nova, 17/X/1990, Freira- } \\
\text { Fierro et al. } 1971 \text { (SPF) }\end{array}$ \\
\hline Pseudobombax tomentosum (Mart. \& Zucc.) A. Robyns & $\begin{array}{c}1975 \\
(1950-2020)\end{array}$ & $\begin{array}{c}435 \\
(370-600)\end{array}$ & $6-8$ & $\begin{array}{c}13,9 \\
(11-18)\end{array}$ & $\begin{array}{l}\text { BRASIL. Bahia: Cocos, 16/V/2001, França et } \\
\text { al. } 3629 \text { (HUEFS) }\end{array}$ \\
\hline
\end{tabular}

1. As espécies novas de Pseudobombax foram denominadas pelos nomes que serão validamente publicadas em "Carvalho-Sobrinho, J.G. \& Queiroz, L.P. Three new species of Pseudobombax (Malvaceae, Bombacoideae) from Brazil. Novon (no prelo)".

2. Média $(\mathrm{n}=10)$. Entre parênteses os valores mínimo e máximo para o parâmetro analisado.

estar dispostas em várias direções, sendo então, chamados de tricomas multiangulados (Theobald et al. 1950; Hewson 1988). De certo modo, há um consenso quanto à sua forma, que deve assemelhar-se à de uma estrela, com raios que divergem de um único ponto (Theobald et al. 1950; Esau 1965; Fahn 1974; Payne 1978; Hewson 1988; Alquini et al. 2003).

Tricomas com morfologia semelhante à encontrada na face abaxial das pétalas de Pseudobombax têm sido denominados como tricomas estrelados (e.g. Theobald et al. 1950), tricomas em buquê (Robyns 1963), tricomas tufosos (Esau 1965) ou tricomas dendríticos (e.g. Payne 1978).

Os tricomas das pétalas de Pseudobombax não apresentam características morfológicas que permitam enquadrá-los como tricomas estrelados. No que diz respeito aos tricomas adultos das espécies aqui estudadas, não se observa um único ponto de divergência dos raios que caracteriza o tricoma estrelado. Além disso, no que se refere à ontogenia, para outros táxons de Malvales, Uphof (1962) considerou que cada ramo unicelular de um tricoma semelhante ao aqui descrito origina-se a partir de divisões anticlinais de uma mesma célula da protoderme e que as bases destas células permanecem unidas após o seu crescimento.

Esau (1965) denominou de tufosos os tricomas observados em Quercus (Fagaceae), os quais apresentam morfologia similar aos de Pseudobombax. Payne (1978) não reconheceu os tricomas tufosos como um dos tipos de tricoma em separado, contudo o tipo dendrítico é o que mais se assemelha com os tricomas de Pseudobombax no sistema de classificação estabelecido por esse autor. Contudo, a condição unicelular dos ramos dos tricomas de Pseudobombax é um grande diferencial impeditivo da adoção desse termo.

Robyns (1963) utilizou o termo "tricomas em buquê" para designar os tricomas das pétalas de Pseudobombax. No presente estudo, preferiu-se não utilizar essa denominação por considerá-la por demais vaga, não apresentar informações quanto à condição celular dos tricomas e não representar uma categoria de uso universal. Assim, optou-se pelo uso do termo tufoso para designar os tricomas encontrados na face abaxial das pétalas das espécies de Pseudobombax, concordando com seu uso em outros grupos taxonômicos, como por exemplo em Quercus (Esau 1965) para tricomas de morfologia semelhante. Assim evita-se também incorrer no erro da indicação, implícita no termo estrelado, de um ponto de divergência único para cada ramo do tricoma.

Aplicação taxonômica - Os tricomas 2-4-armados observados na face adaxial das espécies de Pseudobombax enquadraram-se no conceito dos tricomas 2-5-armados definido por Theobald et al. (1950). Esses autores fizeram referência ao potencial taxonômico desses tricomas, sendo que o número de ramos podendo variar em um mesmo táxon.

Neste estudo, a presença desses tricomas apenas na face adaxial das pétalas das espécies analisadas apresentou-se bastante característica e permitiu reconhecer, com base em seu comprimento, dois grupos de espécies: um formado por $P$. marginatum e $P$. tomentosum, cujos tricomas 2-4-armados apresentam comprimento médio de 1.144-1.975 $\mu \mathrm{m}$, 

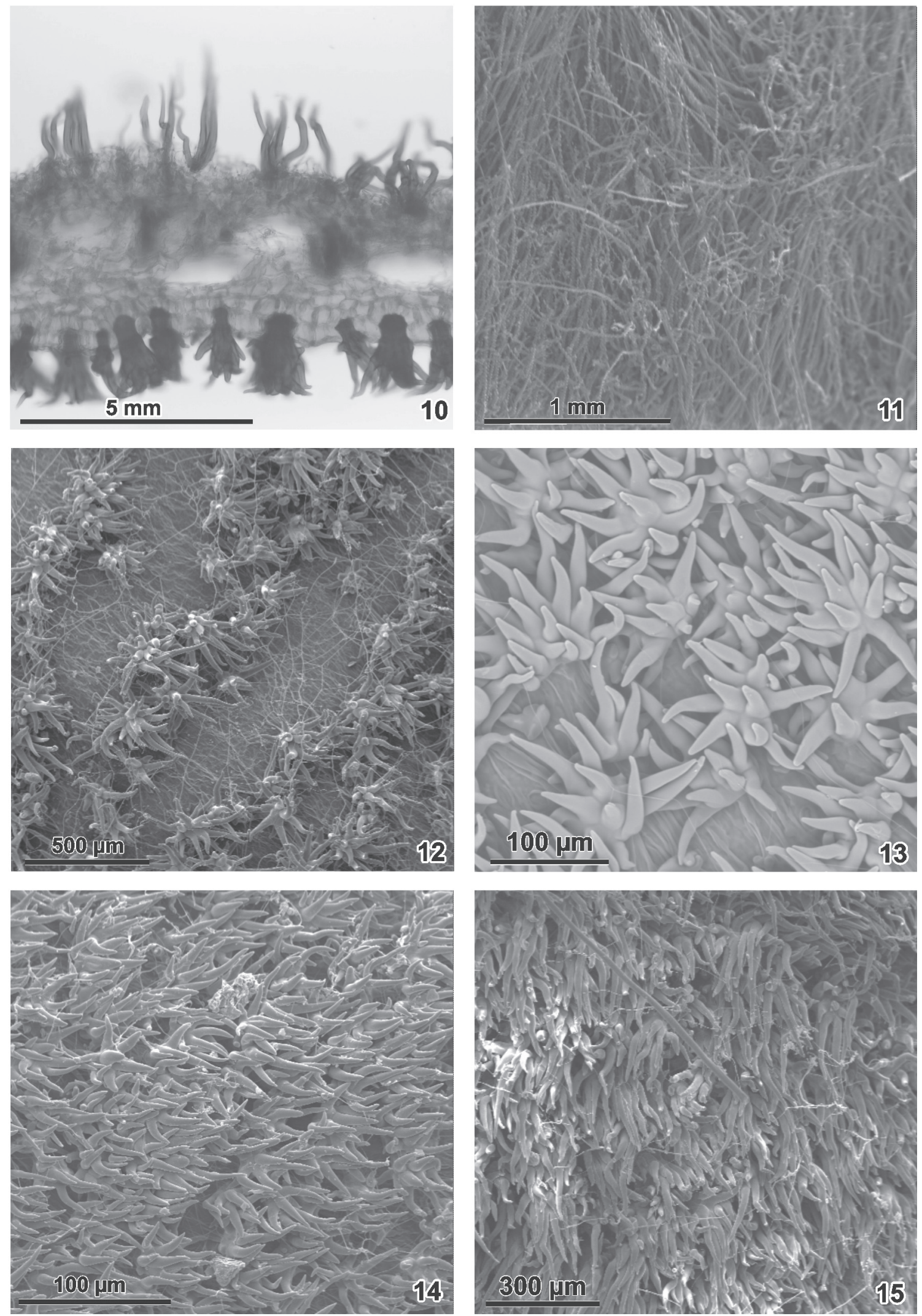

Figuras 10-15. Tipos de indumento nas pétalas de Pseudobombax Dugand. 10. P. grandiflorum: seção transversal da pétala, padrão de distribuição dos tricomas 2-4-armados e tricomas tufosos, respectivamente nas faces adaxial e abaxial. 11. P. marginatum: indumento formado por tricomas 2-4-armados na face adaxial. 12-15. Indumento de tricomas tufosos. 12. P. grandiflorum: tricomas mais densos que em P. longiflorum. 13. P. longiflorum: menor densidade relativa. 14-15. P. marginatum e P. tomentosum, respectivamente, tricomas muito longos. (Fig. 11-15: MEV). 
e outro, constituído pelas demais espécies analisadas, no qual tais tricomas apresentam comprimento médio entre 475 a $850 \mu \mathrm{m}$.

No segundo grupo, o comprimento médio dos tricomas 2-4-armados permite distinguir Pseudobombax campestre e $P$. longiflorum das demais espécies por apresentarem tricomas mais curtos. $P$. campestre e $P$. longiflorum apresentaram também tricomas tufosos de comprimento e número de ramos equivalentes, distinguindo-se das demais espécies por apresentar de 8 a 18 ramos, chegando até $25 \mathrm{em} P$. campestre. $P$. longiflorum pode ser distinguida de $P$. campestre pela menor densidade de tricomas.

A morfologia dos tricomas tufosos permitiu definir um grupo de espécies formado por $P$. grandiflorum, P. longiflorum e $P$. campestre, que é caracterizado pela presença de tricomas tufosos com maior amplitude de número de ramos (8-25) em oposição ao grupo formado pelas demais espécies (6-13 ramos).

Quanto à separação de Pseudobombax longiflorum e $P$. grandiflorum, verificou-se que essas espécies apresentaram tricomas morfologicamente similares em ambas as faces das pétalas. Porém, $P$. grandiflorum apresentou tricomas maiores na face adaxial e maior densidade de tricomas tufosos na face abaxial do que $P$. longiflorum.

Em relação à $P$. marginatum e $P$. tomentosum, apenas os valores de densidade de tricomas tufosos mostraram-se equivalentes nesses dois táxons. $P$. tomentosum apresentou tricomas maiores, tanto os tufosos quanto os 2-4-armados, do que $P$. marginatum, além de apresentar tricomas tufosos com menor número de ramos. Além disso, os tricomas tufosos de $P$. marginatum apresentam a base proporcionalmente maior que o corpo, enquanto $P$. tomentosum distingue-se pelos tricomas tufosos muito mais longos do que largos, com corpo maior do que a base, e ramos mais longos, em sua maioria formando ângulos menores que $20^{\circ}$ em relação ao seu eixo.

Assim, os dados qualitativos e quantitativos obtidos para os tricomas das pétalas mostraram-se de valor taxonômico para a resolução de problemas de identificação específica em Pseudobombax (Malvaceae).

\section{Agradecimentos}

À CAPES pela bolsa de mestrado concedida ao primeiro autor; à Dra. Berta Lange de Morretes e ao Dr. Jomar Gomes Jardim pelas sugestões; à Dra. Kelly Regina Leite e à Dra. Nádia Roque pelas sugestões e revisão do texto. Aos dois revisores anônimos da ABB pelas correções e sugestões.

\section{Referências bibliográficas}

Alquini, Y.; Bona, C.; Boeger, M.R.T.; Costa, C.G. \& Barros, C.F. 2003. Epiderme. In: B. Apezzato-da-Gloria \& S.M. Carmello-Guerreiro (eds.). Anatomia Vegetal. Viçosa, UFV. 438p.

APG II. 2003. An update of the Angiosperm Phylogeny Group classification for the orders and families of flowering plants. Botanical Journal of the Linnean Society 141: 399-436.
Alverson, W.S.; Whitlock, B.A.; Nyffeler, R.; Bayer, C. \& Baum, D.A. 1999. Phylogeny of the core Malvales: evidence from $n d h f$ sequence data. American Journal of Botany 86(10): 1474-1486.

Batterman, M.R.W. \& Lammers, T.G. 2004. Branched foliar trichomes of Lobelioideae (Campanulaceae) and infrageneric classification of Centropogon. Systematic Botany 29(2): 448-458.

Baum, D.A.; Smith, S.D.; Yen, A.; Alverson, W.; Nyffeler, R.; Whitlock, B.A. \& Oldham, R.L. 2004. Phylogenetic relationships of Malvatheca (Bombacoideae and Malvoideae; Malvaceae sensu lato) as inferred from plastid DNA sequences. American Journal of Botany 91(11): 1863-1871.

Bayer, C.; Fay, M.; Bruijn, A.; Savolainen, V.; Morton, C.; Kubitzki, K.; Alverson, W. \& Chase, M. 1999. Support for an expanded family concept of Malvaceae within a recircumscribed order Malvales: a combined analysis of plastid atpb and rbcl DNA sequences. Botanical Journal of the Linnean Society 129(4): 267-303.

Demissew, S. \& Harley, M.M. 1992. Trichome, seed surface and pollen characters in Stachys (Lamiodeae: Labiatae) in Tropical Africa. Pp. 149-166. In: R.M. Harley \& T. Reynolds (eds.), Advances in Labiatae Science. Royal Botanic Gardens, Kew.

Esau, K. 1965. Plant anatomy. $2^{\text {nd }}$ edition. New York, John Wiley \& Sons, Inc. $767 \mathrm{p}$.

Esteves, G.L. 1998. The genus Pavonia Cav. (Malvaceae) in northeastern Brazil. Brittonia 11: 161-235.

Esteves, G.L. 2001. O gênero Pavonia Cav. (Malvaceae) na região sudeste do Brasil. Boletim do Instituto de Botânica 15: 125-194.

Fahn, A. 1974. Plant anatomy. $2^{\text {nd }}$ edition. Oxford, Pergamon Press. 611p.

Fernández-Alonso, J.L. 2001. Bombacaceae neotropicae novae vel minus cognitae 5. Novedades en Pseudobombax Dugand y sinopsis de las especies Colombianas. Revista de la Academia Colombiana de Ciencias Exactas, Físicas y Naturales 25(97): 467-476.

Foster, A.S. 1966. Pratical plant anatomy. $2^{\text {nd }}$ edition. New Jersey, D. Van Nostrand Company, Inc. 228p.

Guimarães, P.J.F.; Ranga, N.T. \& Martins, A.B. 1999. Morfologia dos tricomas em Tibouchina sect. Pleroma (D. Don) Cogn. (Melastomataceae). Brazilian Archives of Biology and Technology 42(4): 485-493.

Hewson, H.J. 1988. Plant indumentum: a handbook of terminology. Australian Flora and fauna series 9. Australian Government Publishing Service, Canberra.

Hummel, K. \& Staesche, K. Die. 1962. Verbreitung der Haartypen in den natürlichen Verwandtschaftsgruppen. Berlin, Gebruder Borntraeger. 292p.

Inamdar, J.A. \& Chohan, A.J. 1969. Epidermal structure and stomatal development in some Malvaceae and Bombacaceae. Annals of Botany 33(132): 865-878.

Macêdo, N.A. 1997. Manual de técnicas em histologia vegetal. Universidade Estadual de Feira de Santana, Bahia. 68p.

Nyfeller, R.; Bayer, C.; Alverson, W.; Yen, A.; Whitlock, B.; Chase, M. \& Baum, D. 2005. Phylogenetic analysis of the Malvadendrina clade (Malvaceae s.1.) based on plastid DNA sequences. Organisms, diversity and evolution 5: 109-123.

Payne, W.W. 1978. A glossary of plant hair terminology. Brittonia 30 (2): $239-255$

Robyns, A. 1963. Essai de Monographie du genre Bombax L. s.l. (Bombacaceae). Bulletin du Jardin Botanique de l'État à Bruxelles 33(1): 1-315.

Robyns, A. 1967. Botany of the Guayana Highland. Partt VII. Memories of the New York Botanical Garden 17(1): 195.

Salma, I. 1999. The taxonomic significance of trichome morphology in the genus Durio (Bombacaceae). Gardens' Bulletin Singapore 51: 55-70.

Theobald, W.L.; Krahulik, J.L. \& Rollins, R.C. 1950. Trichome description and classification. In: C.R. Metcalf \& L. Chalk. Anatomy of the dycotyledons. v. 1: Systematic anatomy of the leaf and stem, with a brief history of the subject. $2^{\text {nd }}$ edition. Clarendon Press, Oxford.

Uphof, J.C.T. 1962. Plants hairs. Handbuch der Pflanzenanatomie 4(5): 1-206. 